$\xi=-1$

\title{
On the Parameters consideration \& analysis of menderline antenna for wireless sensor networks
}

\author{
Harish Rajurkar ${ }^{1}$, Dr. Sudhir Akojwar ${ }^{2}$ \\ ${ }^{1}$ Research Scholar, Rajiv Gandhi College of Engineering Research \& Technology, Chandrapur, India \\ ${ }^{2}$ Associate Professor, Senior Member IEEE, Government Engineering College. Chandrapur, India \\ *Email: harish529@rediffmail.com
}

\begin{abstract}
The objective of this paper is to present an analysis of menderline monopole antennas, which are applicable to wireless sensor networks in agricultural. In this paper, a $2.4 \mathrm{GHz}$ Menderline Monopole Antenna (MLMA) is proposed for wireless sensors network. This work presents the detailed analysis of menderline antenna and variation of mender line parameter on antenna performance. A MLMA is modeled at $2.4 \mathrm{GHz}$ with substrate of FR4 with dielectric constant ( $\varepsilon r$ ) of 4.4. The performance of the MLMA is enhanced by using optimum geometry. The better performance in terms of bandwidth and impedance matching is found. For the proposed MLMA, the bandwidth of $149 \mathrm{MHz}$ and return loss of $-23.98 \mathrm{~dB}$ is obtained. The proposed work shows good performance of MLMA, in terms of geometric size, bandwidth and return loss which makes it suitable for wireless sensor network.
\end{abstract}

Keywords: Wireless sensor network, MLMA, inset feed, VSWR, Return loss, bandwidth

\section{Introduction}

There has been a significant interest in designing of wireless sensor network with low power, low cost \& small size. Wireless Sensor Network (WSN) attracted the interest of many researchers in last few years.[1] WSN is characterized by nodes with a low profile, limited power and sparse energy resources, which have the ability to collaborate with each other, and to sense, and react to the world that surrounds them. Now a days "Plug \& play" system used in WSN, requires small volume solution. The antennas with low size are always preferred for WSN.MLMA technology provides small volume solution. With the mender line the antenna length can be shortened. MLMA has some advantages, it is electrically small, low profile antenna and has simple structure which gives higher bandwidth [7].The MLMA is the small volume solution over the traditional rectangular or square shape patch antenna. This paper organized as- Section II discusses menderline monopole antenna \& proposed design. Section 2 discusses the mender design, section 3 discusses the results of the proposed antenna $\&$ the effect of mender line spacing $\&$ width on return loss, gain, VSWR \& bandwidth discussed. Section 4 concludes the observations from the proposed MLMA.

\section{Menderline antenna}

Mender line antenna was first invented by J.Rashid \& Chen-To Tai in 1982. MLMA are the most widely used antenna for various wireless sensor networks [WSN]. Now a days, WSN nodes demands small size and wider bandwidth antennas.[3,4] Most of the previous work proposes various methods for reducing the size of the monopole. But the reducing the size of monopole ended up with certain drawbacks of reduction in bandwidth and antenna efficiency. WSN, incorporating a compact size antenna can reduce part of the overall sensor node. According to Harold A.Wheeler [5]. A compact antenna defined as an antenna occupying a small fraction of one radiansphere in space and its greatest dimension is less than one-quarter wavelength. As MLMAs are radiating in all directions, they are preferred for WSN. In general the size reduction techniques in resonant antennas can be categorized into three classes, [6]

a) The geometrical deformation of the antenna

b) The insertion of various types of lumped loads

c) The use of different coating materials

In the proposed design, size reduction is achieved by the geometrical deformation of the antenna. MLMA are the antenna with a conductor which is folded back and forth (horizontal and vertical direction) to get required resonance. The some of the important parameters that must be considered for designing MLMA are, number of turns (N), mender spacing (S) \& width (W).The basic structure of a MLA is shown in the figure 1.The resonant frequency of the MLMA can be calculated by using following equations.

$\frac{c}{4 f \sqrt{\zeta r}}\left[\log \left(\frac{2 c}{b f \sqrt{\zeta r}}\right)-1\right]=N w \log \left(\frac{2 l}{N b}\right)+\left[\log \left(\frac{8 l}{b}\right)-1\right]$

Where $f$ is resonant frequency, $c$ is the speed of light, $w$ is antenna width, $l$ is antenna length, $a$ is the pitch, $b$ is conductor diameter \& $N$ is the number of turns. The width of the patch can be determined by following equations following equation.

$w p=\frac{c}{f} \sqrt{(2 / \zeta r+1)}$ 


$$
\begin{aligned}
& L=\frac{c}{2 f \sqrt{\zeta r}}-2 \Delta L \\
& \Delta L=\left(\frac{\zeta r+1}{2}\right)+\left(\frac{\zeta r-1}{2}\right)\left[\frac{1}{\sqrt{1+\frac{12 h}{w p}}}\right.
\end{aligned}
$$

Where wp \& L are width and length of parch ,h is height of substrate [8]

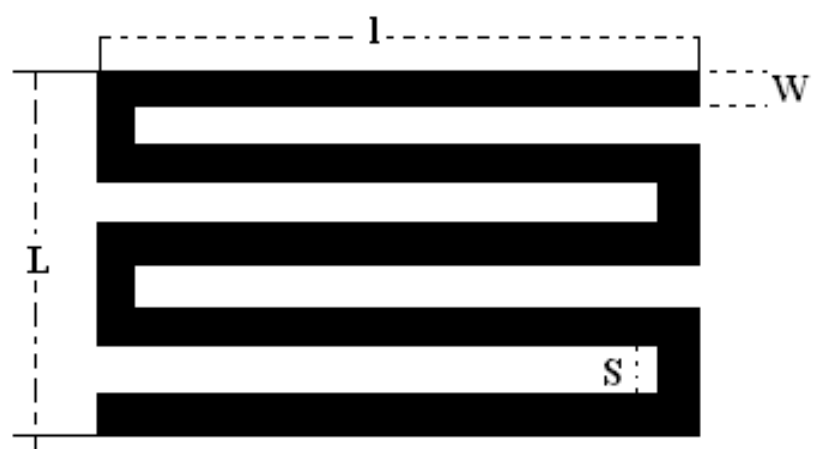

Fig.1 : Mender line structure

\subsection{Design of MLMA}

This work proposes, MLMA, that satisfied the requirements like Impedance, Gain, Radiation pattern for WSN at $2.4 \mathrm{GHz}$. The proposed antenna is printed one side by patch and another side by ground plane. Insect feed is used as it is easier to fabricate. The microstrip feed line excites the center of the slot formed by the edge of patch that to which it is connected. The antenna is simulated by using a substrate of FR4 with dielectric constant $(\zeta \mathrm{r}$ ) of 4.4 and height $(\mathrm{h})$ of $1.59 \mathrm{~mm}$. The optimized parameters of proposed microstrip patch antenna are shown in fig $1 \&$ fig. 2 . The geometry of the designed MLMA is illustrated in figure1.The antenna parameters are calculated as in $[7,8]$.The width and spacing of the antenna is $0.62 \mathrm{~mm}$, the length of mender line is $9.6 \mathrm{~mm}$ and spacing is $1.6 \mathrm{~mm}$. For Impedance matching quarter wave transformer is used. The length of the last mender line is $7.6 \mathrm{~mm}$.
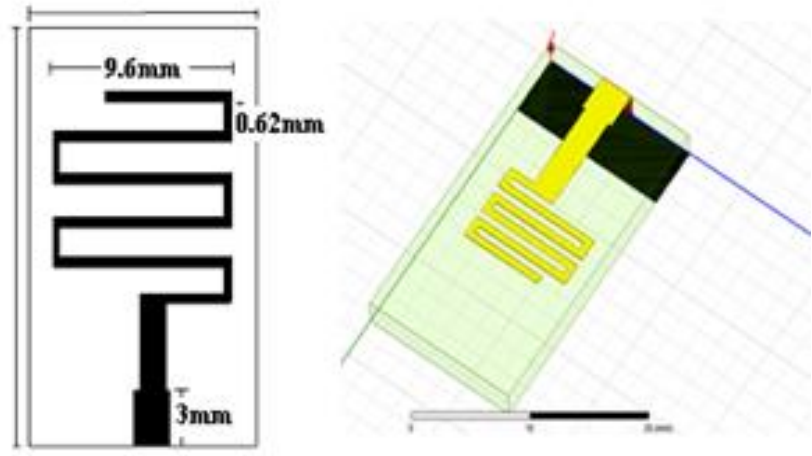

Fig. 2 : Structure of proposed design

\section{Results \& Discussions}

The radiation gain plot is shown in figure 3.The gain of $-3.64 \mathrm{~dB}$ is obtained.

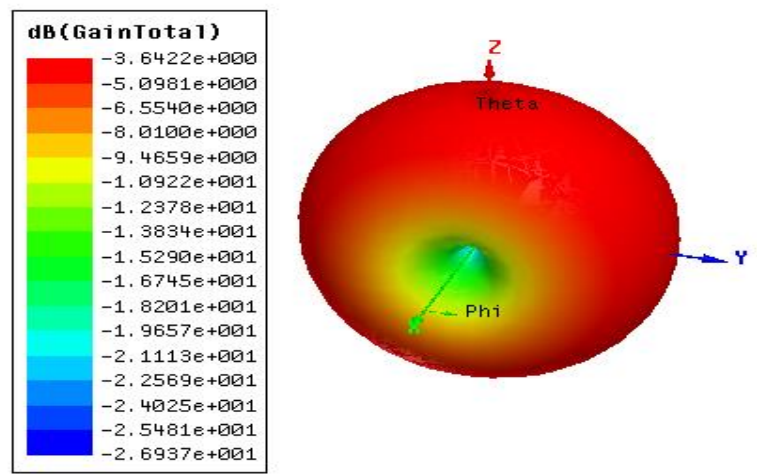

Fig. 3 : 3D gain plot

It is found that, the proposed antenna is well matched to the $50 \Omega$ impedance \& gives return loss of $-23.98 \mathrm{~dB}$ at $2.4 \mathrm{GHz}$ which is lower than $-10 \mathrm{~dB}$.(Fig .4). The agreements between return loss and frequency is good. A bandwidth of $149 \mathrm{MHz}$ is obtained with calculated antenna parameter.The VSWR of 1.13 is found at 2.4 $\mathrm{GHz}$ resonating frequency. (Fig .5).

The results of proposed design of MLMA are tabulated in table 1.

Table1: Summery of proposed Antenna

\begin{tabular}{|c|c|}
\hline Proposed MLMA Parameter & Proposed values/ Results \\
\hline Length of MLMA & $13.7 \mathrm{~mm}$ \\
\hline Mender line length & $9.6 \mathrm{~mm}$ \\
\hline Spacing & $0.62 \mathrm{~mm}$ \\
\hline Width & $0.62 \mathrm{~mm}$ \\
\hline Return Loss & $-23.98 \mathrm{~dB}$ \\
\hline Bandwidth & $149 \mathrm{MHz}$ \\
\hline VSWR & 1.13 \\
\hline Gain & $-3.59 \mathrm{~dB}$ \\
\hline
\end{tabular}

\subsection{Effect of spacing between menderline}

In the proposed design when the spacing between the mender lines is varied keeping other parameter constant, it is observed that (fig.6) the resonant frequency is shift in right direction, bandwidth decreases and the return loss increases. The maximum return loss of $-23.98 \mathrm{~dB}$ is obtained at $2.4 \mathrm{GHz}$. For all the values of spacing between the mender lines more than $0.62 \mathrm{~mm}$ the resonant frequency shift towards left side and return loss increase i.e. shift upwards. It is observed that (fig.6) from 0.62 to $0.82 \mathrm{~mm}$, the return loss shifts upward but the resonant frequency remains the same and bandwidth decreases. But after the $0.82 \mathrm{~mm}$ of spacing the capacitance drastically changed and the sudden change in resonant frequency and return loss is observed,Fig.6.The reason for above is that, the mender line antenna acts as LC resonant circuit where vertical element acts as inductor and horizontal element acts as capacitor. So here when the spacing between mender lines is increases the capacitance between menderline also decreases that's why with the increase in spacing resonant frequency increases and return loss decreases. Hence, for mender line antenna the spacing between the menderline affect the resonant frequency, bandwidth and return loss and hence the impedance matching. It can be concluded that as the mender spacing is increases, the resonant frequency decreases. The optimum value of $\mathrm{S} 11$ of $25.28 \mathrm{~dB}$ is obtained at $2.4 \mathrm{GHz}$ keeping other parameter

\subsection{Effect of variations in width of menderline}

In this case the width of the mender line is varied from 0.52 to $1.02 \mathrm{~mm}$ without change in the other parameter. It is observed 
from the figure 7, that the resonant frequency is shift toward right side as the width of the mender line is increases. There is not much change in the return loss but there is change in the resonant frequency \& the bandwidth also increases. This result shows that substantial size reduction is possible with mender line antenna by keeping its width small. But the reduction in width should be optimum because further reduction in width may cause increase in undesirable radiation from the antenna. The details of the observations with the change in the menderline width are tabulated in table 2. For the fixed mender spacing, change in resonant frequency, return loss and bandwidth are tabulated for variations in mender width.

Table 2. Comparison-Effect of width on MLMA parameter

\begin{tabular}{|c|c|c|c|c|}
\hline $\begin{array}{c}\text { Spacing } \\
(\mathbf{m m})\end{array}$ & $\begin{array}{c}\text { Width } \\
(\mathbf{m m})\end{array}$ & $\begin{array}{c}\text { Resonant } \\
\text { frequency } \\
(\mathbf{G H z})\end{array}$ & $\begin{array}{c}\text { Return } \\
\text { loss (dB) }\end{array}$ & $\begin{array}{c}\text { Bandwidth } \\
(\mathbf{M H z})\end{array}$ \\
\hline 0.62 & 0.62 & 2.4 & -23.98 & 149 \\
\hline 0.62 & 0.72 & 2.5 & -23.57 & 181.7 \\
\hline 0.62 & 0.82 & 2.6 & -23.04 & 228.8 \\
\hline
\end{tabular}

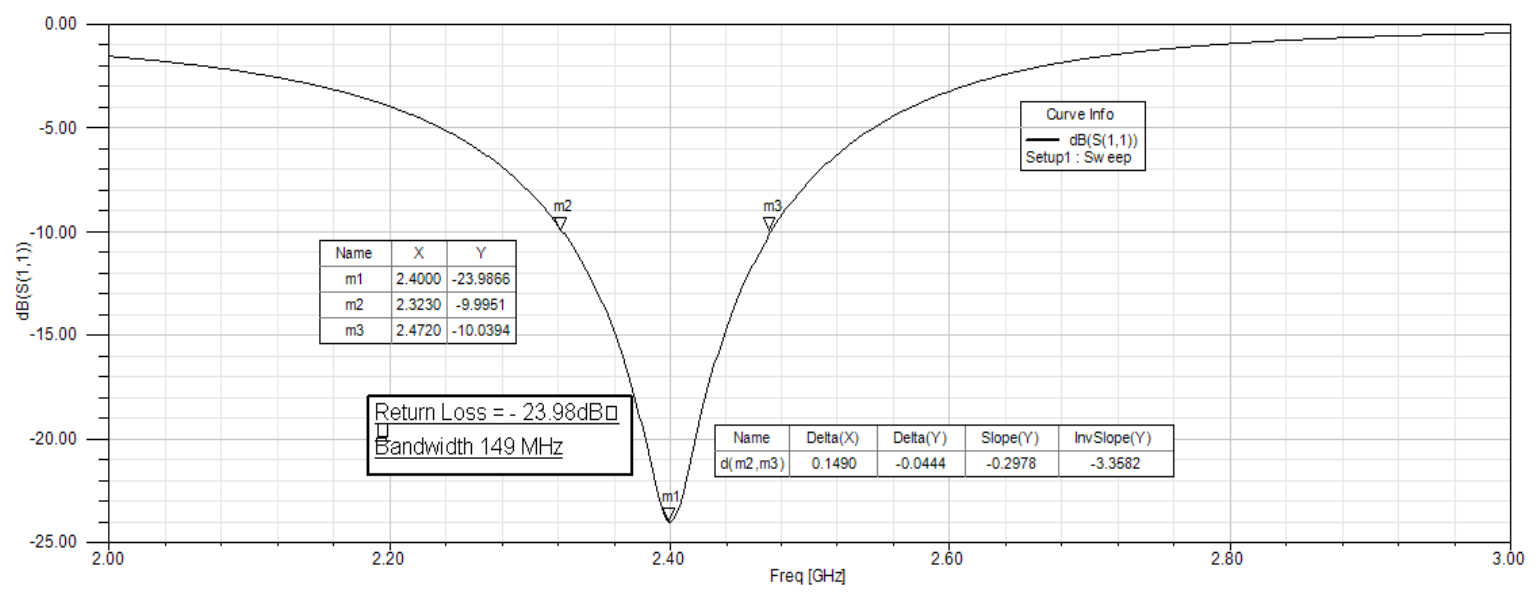

Fig. 4: Return loss of proposed antenna

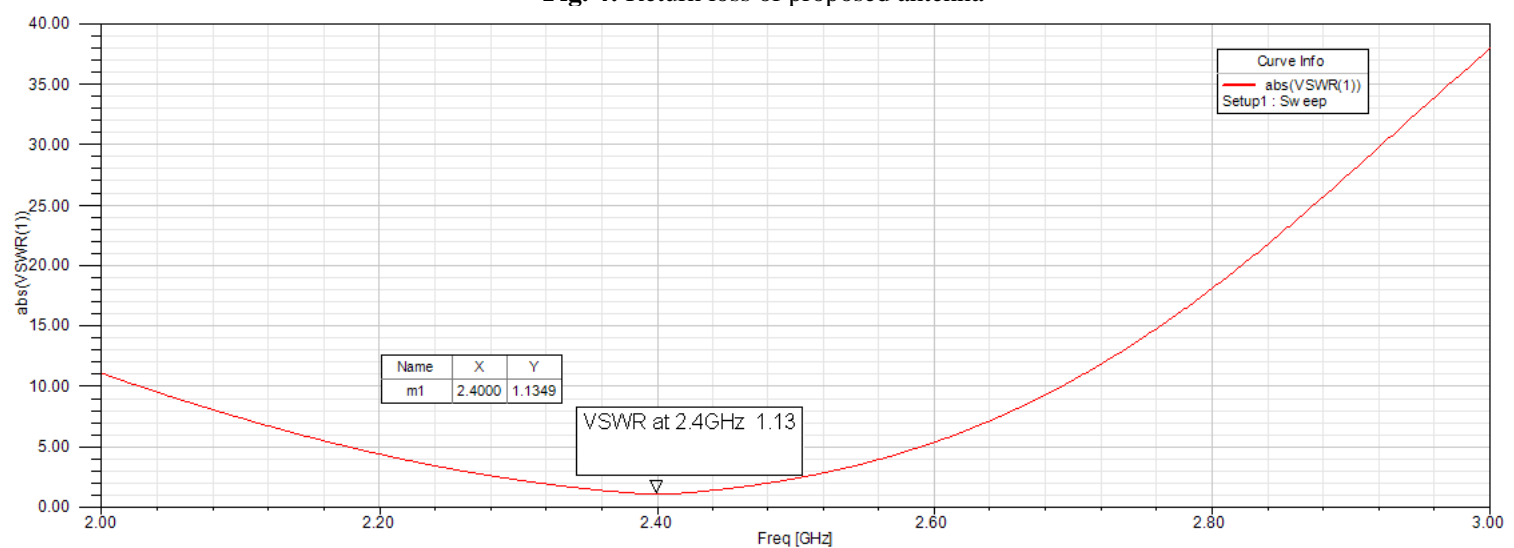

Fig. 5 : VSWR of proposed antenna

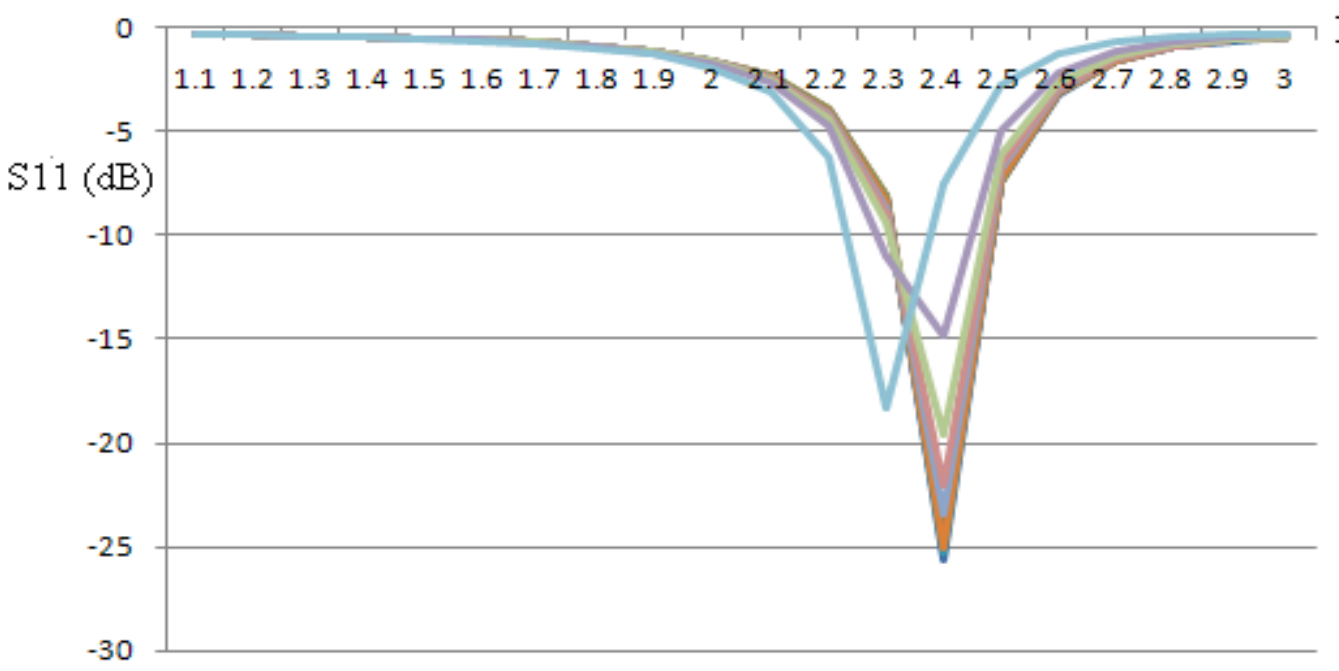

Freq. $(\mathrm{GHz})$

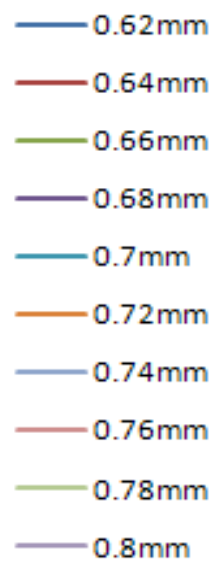

Fig. 6 : Return loss Vs frequency ( Variations in menderline spacing) 


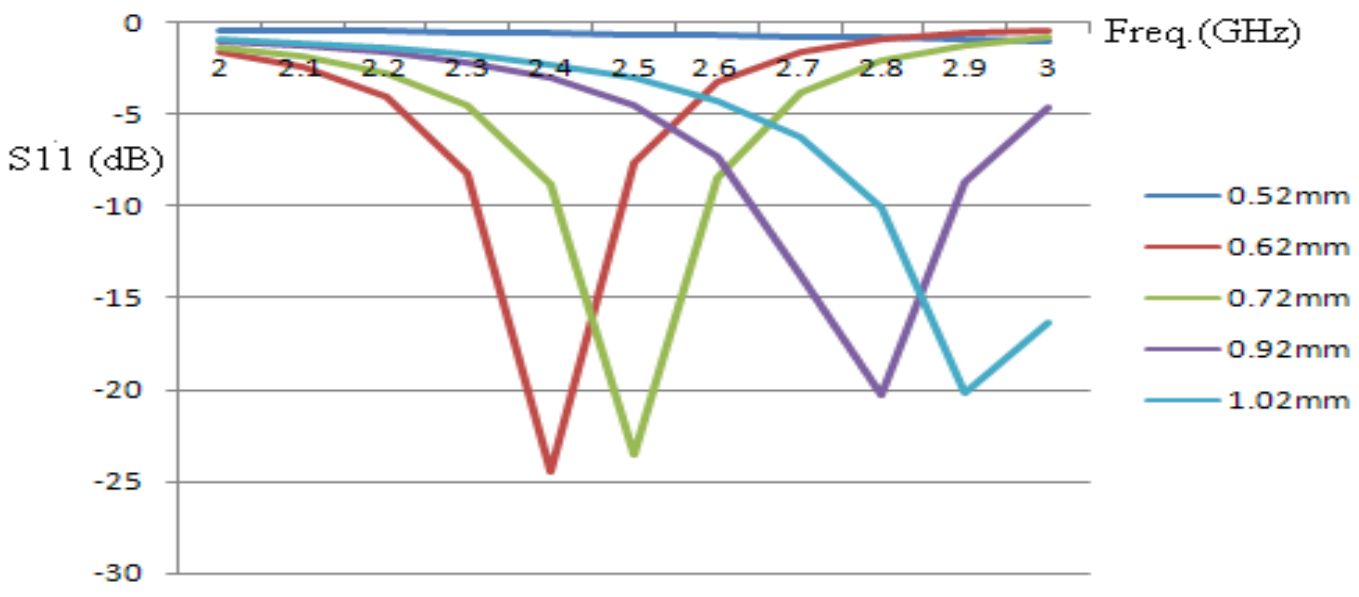

Fig. 7: Return loss Vs frequency (variations in mender width)

\section{Conclusion}

The purpose of this paper is to focus on the mender parameters consideration and its effects on resonant frequency \& return loss. The proposed antenna is designed for $2.4 \mathrm{GHz}$ frequency. The designed is well suited for wireless sensor network. The return loss of $-23.98 \mathrm{~dB}$ is obtained at $2.4 \mathrm{GHz}$ with bandwidth of $149 \mathrm{MHz} \&$ VSWR of 1.13 . The parametric analysis of the menderline monopole is done with the variation in menderline width and spacing. From the analysis it is observed that with the increase in the menderline width, the resonant frequency shift towards left side and return loss increase i.e. shift upwards. It is also observed that with the increase in the spacing between menderline, the resonant frequency increases but return loss decrease results in poor impedance matching. In view of simple path antenna which is mostly used in WSN nodes, herein the proposed antenna has the advantages that its size is comparatively small [9] which is a very essential for reducing the size of overall sensor node. Thus from the proposed design it is concluded that the size reduction is possible using menderline antenna.

\section{Acknowledgement}

The authors gratefully acknowledge the facilities provided by Rajeev Gandhi College of Engineering, Research \& Technology, Chandrapur, India

\section{References}

[1] Zakaria Z, N A Zainuddin, M Z A Abd Aziz, Husain M.N \& Mutalib M A 2013 A Parametric Study on Dual-Band Meander Line Monopole Antenna for RF Energy Harvesting. In: Proceeding of the IEEE Int .Conference on RFID Technologies and Applications, Johor Bahru, Malaysia.

[2] Skiani E D, Mitilineos S A \& Thomopoulos S C A 2012 A Study of the Performance of Wireless Sensor Networks Operating with Smart Antennas. In: IEEE J. Antennas and Propagation Magazine, Vol. 54, No. 3

[3] Ray K P \& Kumar Girish 2014 Broadband microstrip antenna In: Artech House- antennas and propagation library, 2014. ISBN 158053-244-6.

[4] Ahmad El Sayed, Jean-Marie Floc'hUltra 2013 Wideband QuasiYagi Circular Dipole Antenna for Wireless Applications. In Antennas \&
[5] Baharun Azwa , Naffashsa 2013 Meander line antenna for wireless sensor network application In: PhD Thesis, Faculty of Electrical Engineering, University Technology, Malaysia, June 2013

[6] Jalil Agha \& Rashed Mohassel 2013 Mender Antenna. In: Ph D thesis, department of electrical engineering, University of Michigam,, pp. 22-24

[7] P N Calla, Alok Singh, Amit Kumar Singh, Sandeep Kumar \& Triloki Kumar, 2008 Relation for Designing the Meander Line Antenna. In:proceeding of international conference on microwave, IEEE, pp. 203-204

[8] Balanis C A 2005 Antenna Theory, Analysis \& Design 3rd edition Wiley India Edition New Delhi, chapter 14, pp. 811-886

[9] Qun, Deng, Weiqiang Zhang \& Jintao, Jiang 2013 Design and simulation of the microstrip antenna for $2.4 \mathrm{GHz} \mathrm{HM}$ remote. In: proceedings of int. conference on system, modeling and design, 2013.pp. 103-105 